\title{
Acceptance of artificial nesting sites by pollinating mason bees in commercial fruit plantations (Hymenoptera, Megachilidae: mixed Osmia cornuta and $O$. rufa population)
}

\author{
Benedek, P. ${ }^{1}$, Nyéki, J. ${ }^{2}$, Soltész, M. ${ }^{2}$, Szabó, T. $^{3}$ \& Konrádné, C. ${ }^{4}$ \\ ${ }^{1}$ University of West Hungary, Faculty of Agricultural ad food Sciences, \\ H-9200 Mosonmagyaróvár, Vár 4. (e-mail: benedek@mtk.nyme.hu) \\ ${ }^{2}$ Institute of Extension and Development, University of Debrecen, H-4032 Debrecen, Böszörményi út 138. \\ ${ }^{3}$ Research and Extension Centre for Fruit Growing, H-4244 Ujfehértó, Vadastag 2. \\ ${ }^{4}$ Gyümölcskert Zrt., H-8800 Nagykanizsa, Csengery út 90.
}

\begin{abstract}
Summary: During a four yeas long experiment a simple bee shelters was found to be a proper method to increase the size of mixed natural populations of the early season Osmia cornuta and $O$. rufa under practical farm conditions. Instead of the number of pesticide applications the earliness of the flowering of the fruit species in the orchards was found to be the most important factor in the rate of acceptance of reed as nesting medium by Osmias in the bee shelter. This relationship was negative and highly significant $(\mathrm{r}=-0.829, \mathrm{p}<0.001)$. This means that much higher acceptance of artificial nesting media in bee shelters and consequently much higher population increase of the two early season mason bee species can be expected in orchards with early than with late flowering fruit species. Mixed orchards or early flowering orchards surrounded by other orchards falling in bloom later consecutively may also be much favourable to mason bees because they can find continuous food (pollen) supply there for a much longer time during their period of activity than in orchards planted with a single fruit species and being apart from orchards of other fruit species.
\end{abstract}

Key words: fruit orchards, bee pollination, flowering time, Osmia cornuta, Osmia rufa, bee shelter, acceptance of nesting sites

\section{Introduction}

The native early spring mason bee species (Osmia cornuta and also $O$. rufa) have been known as effective pollinating agent of fruit trees in Europe (Bosch 1994a, Bosch \& Kemp 2002, Krunic et al. 1995, Maccagnani et al. 2003, Pinzauti 1991, Vincens \& Bosch 2000a). For this reason efforts were made to use artificially reared stocks for controlled fruit tree pollination (Bosch 1994c, 1995, Bosch \& Blas 1994a, b, Krunic et al. 1995, Vincens \& Bosch 2000b, c). On the other hand, in site propagation of native populations has also be found to be a proper (and much cheaper) method to increase pollinating wild bee density around fruit tree plantations (Benedek 2008). Exploiting this finding, we used simple bee shelters to increase natural pollinating wild bee population in some commercial fruit tree plantations and found that the bee shelters were accepted in different rates at different localities in orchards planted with different fruit tree species. These experiences may be important and useful to fruit growers.

\section{Material and method}

The bee shelters ("wild bee hives"): were described in a previous paper (Benedek 2008) as follows: The shelter was made of wooden panels with four compartments open on the

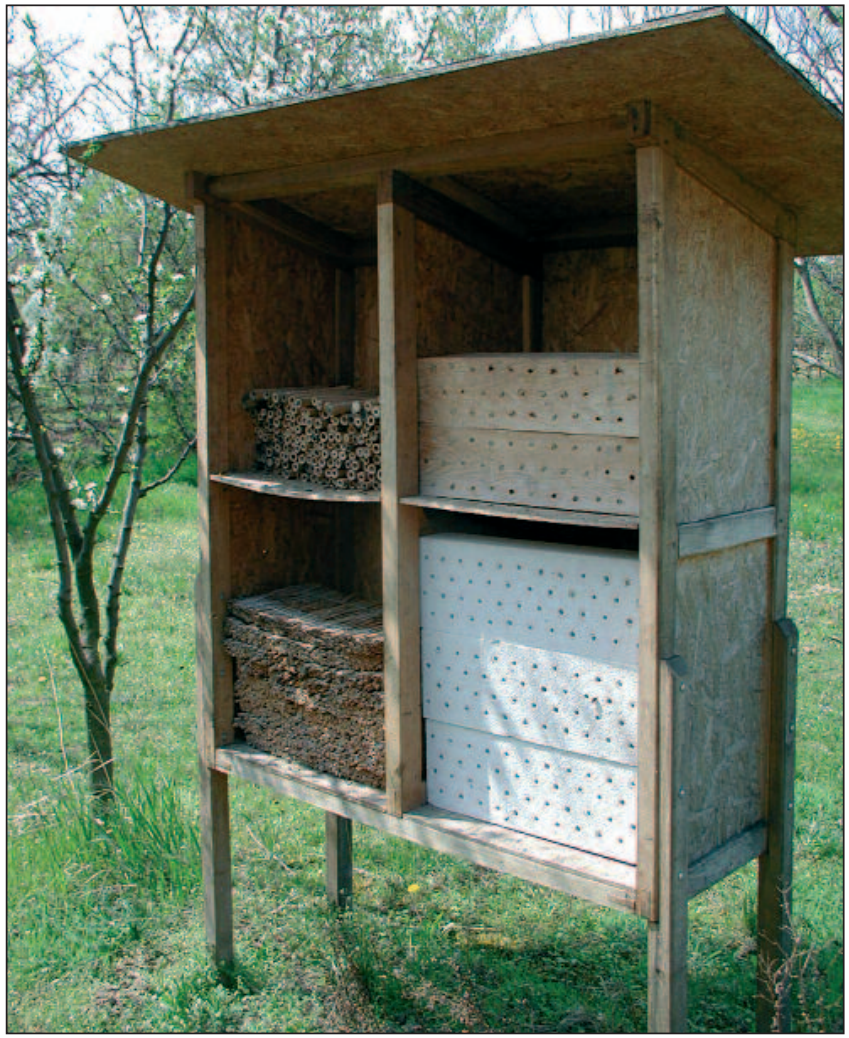

Figure 1. Bee shelter ("wild bee hive") with artificial nesting media for Osmia bees 
front side and covered elsewhere (Fig. 1.). The shelters had a roof covering the top against rainfall. The shelters had four legs keeping a $60 \mathrm{~cm}$ distance between the lower compartments and the soil surface to prevent field rodents to settle. Each shelter was facing south-west with the open front. The shelters were placed by that side of the fruit plantations where no pesticide applications were made at the neighbouring vicinity to prevent direct contact with pesticide applications during the growing season. A single bee shelter was placed at each site.

Nesting media in the shelters: One to four kinds of nesting media were used. Where four kinds were used, one of the four compartments was filled with reed having been cut to some $40 \mathrm{~cm}$ long pieces. The inner diameter of the reed was some $6-10 \mathrm{~mm}$. One other compartment was used for nesting medium of $25 \times 25 \mathrm{~cm}$ wide hardwood blocks with 10 $\mathrm{cm}$ long drilled holes of $8 \mathrm{~mm}$ inner diameter. The third compartment was used for a nesting medium made of lightweight walling blocks with similar drilled holes at the front as well as the rear sides as with the hardwood blocks. Finally a fourth kind of nesting medium was also used in one of the experiments where one compartment was partly filled with $40 \mathrm{~cm}$ long pieces of bamboo rods, with inner hole diameter of some $7-10 \mathrm{~mm}$.

Where three kinds of nesting media were used, those were the reed, the hardwood blocks and the walling blocks, but the bamboo rods were neglected. At some experiments nothing else than reed was used, because it was suggested to be used in the practice in a previous study (Benedek 2008) and it was the cheapest and the most convenient solution to provide proper nesting conditions in great numbers to mason bees. Bee shelters filled completely with reed contained at least 14.500 tunnels that made $2 \times 14.500=29.000$ nesting holes for bees in the front plus the rear side instead of 1000 when filled with walling blocks and only 115 when filled with hardwood blocks.

Experimental sites: Experiments were carried out at ten fruit plantations at seven different localities from 2006 to 2009.

The first locality was Tök (North Central Hungary), in a fruit and vine garden area outside the settlement. At this place several relatively small mixed orchards and vineyards were surrounding each other. The orchard where the bee shelter was placed was a mixed plantation containing a number of trees of almond, apricot, peach, cherries, plum, apple, pear and quince. The bee shelter was placed at the Southern edge of the plantation. This plantation received some 3-5 pesticide treatments a year, the number of treatments varied according to fruit species.

The second site was Nagykutas (South-West Hungary) where the bee shelter was placed in a large sweet cherry orchard and also large apple orchards were in the close vicinity. The shelter was put $10 \mathrm{~m}$ off the side row of the plantation. This plantation received some 5-7 plant protection treatments all along the growing season.

The third locality was Boldogkőváralja (North-Eastern Hungary) where bee shelter was placed in a large commer- cial apricot plantation surrounded by similar orchard in the close vicinity. This plantation received 3-5 pesticide applications per year.

The fourth site was Siófok (Central Hungary, South-East Balaton area) where the bee shelter was located in a large commercial sour cherry plantation surrounded by apple orchards. The cherry orchard received some 5-7 pesticide application a year.

The fifth locality was Ujfehértó (Eastern Hungary) were the bee shelter was put into a large commercial sour cherry orchard surrounded by other fruit orchards. This orchard received 6-8 pesticide applications a year but some surrounding orchards received as much treatments as 10-14 every year.

The sixth site was Pallag (Eastern Hungary, near Debrecen) where the bee shelter was placed in a large commercial apple orchard that received some 10-12 pesticide.

The seventh place was Nagykanizsa (South-West Hungary) where four bee shelters were placed in large commercial pear plantations each. These plantations received intense pesticide treatments, some 8-10 applications a year.

\section{Observations}

Flowering period of fruit trees was registered in the experimental orchards.

The acceptance of the nesting media was inspected in the bee shelters by the end of the growing seasons, but comparison was only made with the figures obtained in the last year of the experiment (2009). This way the bees were provided time long enough (four years) to establish and build up small local populations in the bee shelters.

The number of available nesting holes was counted at each available nesting media and the number of occupied (covered) nesting holes were carefully counted, too. The per cent ratio of occupied (covered) holes was finally calculated.

\section{Results}

The acceptance of the nesting media in the bee shelters is illustrated in Table 1. Different kinds of nesting media received different rate of acceptance at different sites. Bamboo was applied at one locality only but reed was used at each sites. Acceptance of hardwood block and lightweight walling blocks was greatly variable. Both hardwood block and walling block received the highest rates of acceptance at some localities but their acceptance was the smallest at other instances. No explanation was found of their greatly changeable acceptance and no relationship could be recognized between the rates of acceptance of different kinds of nesting media.

In fact, from the practical point of view, only the acceptance of reed is important because - as mentioned above - this is the cheapest solution to provide proper nesting holes in great numbers to mason bees in fruit orchards. 
Table 1. Acceptance of artificial nesting media by early spring mason bees (mixed Osmia cornuta and O. rufa populations) in bee shelters placed at orchards of different fruit tree species

\begin{tabular}{|c|c|c|c|c|c|}
\hline \multirow[t]{2}{*}{ Site } & \multirow[t]{2}{*}{$\begin{array}{l}\text { Fruit } \\
\text { plantation } \\
\text { (species) }\end{array}$} & \multicolumn{4}{|c|}{$\begin{array}{l}\text { Acceptance of available nesting } \\
\text { media: per cent ratio of occupied } \\
\text { (covered) holes, as compared to } \\
\text { the available capacity }\end{array}$} \\
\hline & & reed & $\begin{array}{l}\text { hard- } \\
\text { wood } \\
\text { blocks } \\
\text { with } \\
\text { artificial } \\
\text { holes }\end{array}$ & \begin{tabular}{|c|} 
light \\
weight \\
(Ytong) \\
walling \\
blocks \\
with \\
artificial \\
holes
\end{tabular} & $\begin{array}{c}\text { bamboo } \\
\text { rods }\end{array}$ \\
\hline Tök & $\begin{array}{l}\text { mixed } \\
\text { plantation: } \\
\text { almond, apricot, } \\
\text { peach, cherries, } \\
\text { plum, apple, } \\
\text { pear, quince }\end{array}$ & $27.8 \%$ & $23.2 \%$ & $2,1 \%$ & $28,6 \%$ \\
\hline Nagykutas & sweet cherry & $27.1 \%$ & $48.6 \%$ & $1.1 \%$ & - \\
\hline Boldogkőváralja & apricot & $14.7 \%$ & $0 \%$ & $18.6 \%$ & - \\
\hline Siófok & sour cherry & $12.7 \%$ & $75.7 \%$ & $50.0 \%$ & - \\
\hline Ujfehértó & sour cherry & $6.9 \%$ & $25.2 \%$ & 0 & - \\
\hline Pallag & apple & $2.8 \%$ & $3.3 \%$ & 0 & - \\
\hline Nagykanizsa & pear No1. & $6.3 \%$ & - & - & - \\
\hline Nagykanizsa & pear No2. & $2.7 \%$ & - & - & - \\
\hline Nagykanizsa & pear No3. & $2.6 \%$ & - & - & - \\
\hline Nagykanizsa & pear No4. & $1.3 \%$ & - & - & - \\
\hline
\end{tabular}

Analysing the figures relating to the acceptance of reed much higher figures can bee seen in orchard where early flowering fruit species (almond, apricot, cherries) were present than in orchard with fruit species flowering later on (apple, pear). Correlating the flowering time of fruit species and the rates of acceptance of reed as nesting medium a very close negative relationship was found, where the correlation coefficient was very high and highly significant $(r=-0.829$, $p<0.001$ ). In this calculation the serial numbers of days of the year counted from the first of January were taken into account (for example when the flowering started on the on the $10^{\text {th }}$ of April that was the day 100 of the year).

\section{Discussion and conclusions}

During a four years long experiment the simple bee shelter recommended to use in commercial orchards (Benedek 2008) was found to be a proper method to increase the size of mixed natural populations of the early season Osmia cornuta and $O$. rufa under practical farm conditions. The rate of acceptance of reed recommended as nesting medium in commercial orchards was greatly different at different places. These differences represented greatly different population increase but even the smallest figures were important because reed provided much more nesting possibilities to bees than the other tested nesting media.
Instead of the number of pesticide applications the earliness of the flowering of the fruit species in the orchards was found to be the most important factor in the rate of acceptance of reed as nesting medium by Osmias. This relationship is negative and highly significant. This means that much higher acceptance of artificial nesting media in bee shelters and consequently much higher population increase of the two early season mason bee species in question can be expected in orchards with early than with late flowering fruit species. In early flowering orchards mason bees can probably become constant visitors of fruit tree flowers from the commencement of their flight period and so they are able to construct more nests in artificial nesting media in artificial shelters placed into the plantation than in late flowering orchards where they are forced to find other pollen sources than fruit flowers in the first week or first few weeks of their flight period. Very probably, in late flowering orchards many of them are forced to leave the site and find nesting possibilities elsewhere. Mixed orchards or early flowering orchards surrounded by other orchards falling in bloom later consecutively may also be much favourable to mason bees because they can find continuous food (pollen) supply there for a much longer time during their period of activity than in orchards planted with a single fruit species and being apart from orchards of other fruit species.

\section{References}

Benedek, P. (2008): Preliminary studies on propagating natural mason bee (mixed Osmia cornuta and O. rufa) populations in artificial media at the sites for fruit orchard pollination. International J. Horticultural Science. 14. (1-2): 95-101.

Bosch, J. (1994a): Osmia cornuta Latr. (Hymenoptera: Megachilidae) as a potential pollinator of almond orchards. J. Appl. Entomol. 117: 151-157.

Bosch, J. (1994b): The nesting behaviour of the mason bee Osmia cornuta (Latr.) with special reference to its pollinating potential (Hymenoptera, Megachilidae. Apidologie. 25: 84-93.

Bosch, J. (1994c): Improvement of field management of Osmia cornuta (Latreille) (Hymenoptera, Megachilidae) to pollinate almond. Apidologie. 25: 71-83.

Bosch, J. \& Blas M. (1994a): Foraging behaviour and pollinating efficiency of Osmia cornuta and Apis mellifera on almond (Hymenoptera, Megachilidae and Apidae). Appl. Entomol. Zool. 29: 1-9.

Bosch J. \& Blas M. (1994b): Effect of over-wintering and incubation temperatures on adult emergence in Osmia cornuta Latr. (Hymenoptera, Megachilidae). Apidologie. 25: 265-277.

Bosch J. \& Kemp W.P. (2002): Developing and establishing bee species as crop pollinators: the example of Osmia spp. (Hymenoptera: Megachilidae) and fruit trees. Bull.

Krunic M., Pinzauti M., Felicioli A. \& Stanisavljevic L.J. (1995): Further observations on Osmia cornuta Latr. and O. rufa L. as alternative fruit pollinators, domestication and utilization. Arch. Biol. Sci., Belgrade. 47: 59-66.

Maccagnani, B., Ladurner, E., Santi, F. \& Burgio, G. (2003): Osmia cornuta (Latreille) (Hymenoptera, Megachilidae) as a pollinator of pear (Pyrus communis L.): fruit- and seed-set. Apidologie. 34: 207-216. 
Pinzauti M. (1991): Possibilità di allevamento controllato di Osmia rufa L. e Osmia cornuta Latr. (Hymenoptera: Megachilidae) per l'impollinazione dei frutteti 1: nota preliminare. Proc. XVI Natl. Italian Congr Entomology, Martina Franca: 537-544.

Vicens N., Bosch J. (2000a): Pollinating efficacy of Osmia cornuta and Apis mellifera (Hymenoptera: Megachilidae, Apidae) on 'Red Delicious' apple. Environ. Entomol. 29: 235-240.
Vicens N., Bosch J. (2000b): Weather-dependent pollinator activity in an apple orchard, with specialreference to Osmia cornuta and Apis mellifera (Hymenoptera: Megachilidae, Apidae). Environ. Entomol. 29: 413-420.

Vicens N., Bosch J. (2000c): Nest site orientation and relocation of populations of the orchard pollinator Osmia cornuta (Hymenoptera: Megachilidae). Environ. Entomol. 29: 69-75. 